\title{
Mono-(2-ethylhexyl) phthalate stimulates basal steroidogenesis by a cAMP-independent mechanism in mouse gonadal cells of both sexes
}

\author{
David Gunnarsson, Per Leffler ${ }^{1}$, Emelie Ekwurtzel, Gunilla Martinsson, Kui Liu ${ }^{2}$ \\ and Gunnar Selstam
}

Department of Molecular Biology, Umeå University, S-901 87 Umeå, Sweden, 'Division of CBRN Defence and
Security, Swedish Defence Research Agency, Department of Threat Assessment, Cementvägen 20, S-901 82 Umeå,
Sweden and ${ }^{2}$ Department of Medical Biochemistry and Biophysics, Umeå University, S-901 87 Umeå, Sweden

Correspondence should be addressed to G Selstam; Email: gunnar.selstam@molbiol.umu.se

\begin{abstract}
Phthalates are widely used as plasticizers in a number of daily-life products. In this study, we investigated the influence of mono(2-ethylhexyl) phthalate (MEHP), the active metabolite of the frequently used plasticizer di-(2-ethylhexyl) phthalate (DEHP), on gonadal steroidogenesis in vitro. MEHP $(25-100 \mu \mathrm{M})$ stimulated basal steroid synthesis in a concentration-dependent manner in immortalized mouse Leydig tumor cells (MLTC-1). The stimulatory effect was also detected in KK-1 granulosa tumor cells. MEHP exposure did not influence cAMP or StAR protein levels and induced a gene expression profile of key steroidogenic proteins different from the one induced by human chorionic gonadotropin (hCG). Simultaneous treatment with MEHP and a p450scc inhibitor (aminoglutethimide) indicated that MEHP exerts its main stimulatory effect prior to pregnenolone formation. MEHP (10-100 $\mu \mathrm{M})$ up-regulated hormone-sensitive lipase and 3-hydroxy-3-methylglutaryl coenzyme A reductase, suggesting that MEHP increases the amount of cholesterol available for steroidogenesis. Our data suggest that MEHP, besides its known inhibitory effect on hCG action, can directly stimulate gonadal steroidogenesis in both sexes through a CAMP- and StAR-independent mechanism. The anti-steroidogenic effect of DEHP has been proposed to cause developmental disorders such as hypospadias and cryptorchidism, whereas a stimulation of steroid synthesis may prematurely initiate the onset of puberty and theoretically affect the hypothalamic-pituitary-gonadal axis.

Reproduction (2008) 135 693-703
\end{abstract}

\section{Introduction}

The prevalence of reproductive disorders such as hypospadias, cryptorchidism, and testicular cancer has increased during the last decades in several Western countries (Lottrup et al. 2006). These disorders are hypothesized to be manifestations of the same underlying prenatal disturbance, the testicular dysgenesis syndrome (TDS; Skakkebaek et al. 2001). Genetic as well as environmental factors are believed to be involved in the etiology of TDS. Among environmental factors, phthalates have been given special focus since exposure is almost unavoidable and phthalates cause a TDS-like phenotype in laboratory animals (Virtanen et al. 2005).

Phthalates are a group of industrial chemicals commonly used as plasticizers in a variety of consumer products, such as polyvinyl chloride (PVC) floors, toys, car interiors, and medical devices. Di-(2-ethylhexyl) phthalate (DEHP) is one of the most frequently used phthalates, and in Western Europe it accounts for $\sim 30 \%$ of all plasticizer usage. It is considered to have a low acute toxicity in several species, including man (Rhodes et al. 1986). However, at high doses, DEHP has been shown to cause developmental and/or reproductive toxicity in a number of mammalian species including rodents (Parks et al. 2000). Lower doses of DEHP appear to give rise to more subtle effects. At doses equivalent to the exposure level in the general population, DEHP can increase testosterone concentrations and reduce sperm production, through a yet unknown mechanism (Andrade et al. 2006). In addition, recent studies indicate a possible relationship between human phthalate exposure and altered development in both males and females (Colon et al. 2000, Swan et al. 2005).

Since DEHP is not chemically bound to the plastic polymer it is continuously released into the atmosphere, food products, or directly into body fluids from medical devices (Koch et al. 2006). The general population is exposed to DEHP primarily through inhalation and ingestion (Silva etal. 2006). The major metabolite of DEHP, mono-(2-ethylhexyl) phthalate (MEHP), is thought to be the active agent in testicular (Sjoberg et al. 1986) as well as ovarian toxicity (Davis et al. 1994b). When ingested orally, 
DEHP is rapidly hydrolyzed by intestinal lipases to MEHP, which is readily absorbed from the gut (Ljungvall et al. 2004). In the airways, DEHP is absorbed as the parent compound and thereafter metabolized to MEHP (Shea 2003). Serum MEHP levels are generally low in the population (50th percentile $=4 \mathrm{ng} / \mathrm{ml}$ ), but markedly higher levels of exposure occur in, for example, patients undergoing intensive care (Kato et al. 2004). Infants are particularly exposed and plasma MEHP levels as high as $15.1 \mu \mathrm{g} / \mathrm{ml}(\approx 54 \mu \mathrm{M})$ have been recorded (Sjoberg et al. 1985).

Previous in vitro studies of phthalate exposure have focused on the effects on human chorionic gonadotropin (hCG)- or 8-Br-cAMP-induced steroidogenesis. Alterations in basal steroid synthesis may be equally important and the objective of this study was to investigate the influence of MEHP on basal steroidogenesis and elucidate mechanisms in male as well as female gonadal cells. For this purpose, immortalized mouse Leydig (MLTC-1) and granulosa (KK-1) tumor cells were used.

\section{Results}

\section{Stimulation of basal steroidogenesis}

In order to examine the influence of MEHP on basal Leydig cell steroidogenesis, MLTC- 1 cells were exposed to MEHP, in the concentration range $10-100 \mu \mathrm{M}$, for $24 \mathrm{~h}$. At the end of exposure, the media were collected and assayed for progesterone and testosterone by dissociation-enhanced lanthanide fluoroimmunoassay (DELFIA). As displayed in Fig. 1A, MEHP stimulated progesterone synthesis in a concentration-dependent manner, with $25 \mu \mathrm{M}$ being the lowest concentration that caused a significant increase (1.7-fold). Maximal stimulation was observed after exposure to $100 \mu \mathrm{M}$ MEHP, where the synthesis was enhanced more than 6 -fold as compared with untreated control cells.

MEHP at a concentration of $25 \mu \mathrm{M}$ was used to analyze the time course of the stimulatory effect. As can be seen in Fig. 2, the first time point at which a statistically significant stimulation could be detected was $12 \mathrm{~h}$. At this time point, MEHP-exposed cells had $\sim 1.2-$ fold higher production of progesterone than control cells. Testosterone synthesis was also elevated by MEHP in the same concentration range $(25-100 \mu \mathrm{M})$, as shown in Fig. 1B. However, the stimulation of testosterone production was less pronounced and reached a maximum of 1.7-fold above control values at 75 and $100 \mu \mathrm{M}$ MEHP. To investigate whether MEHP influenced steroidogenesis in granulosa cells, progesterone was measured also in media collected from KK-1 cells exposed to $100 \mu \mathrm{M}$ MEHP for $24 \mathrm{~h}$ (Fig. 3). MEHP was found to enhance progesterone production with $\sim 120 \%$.
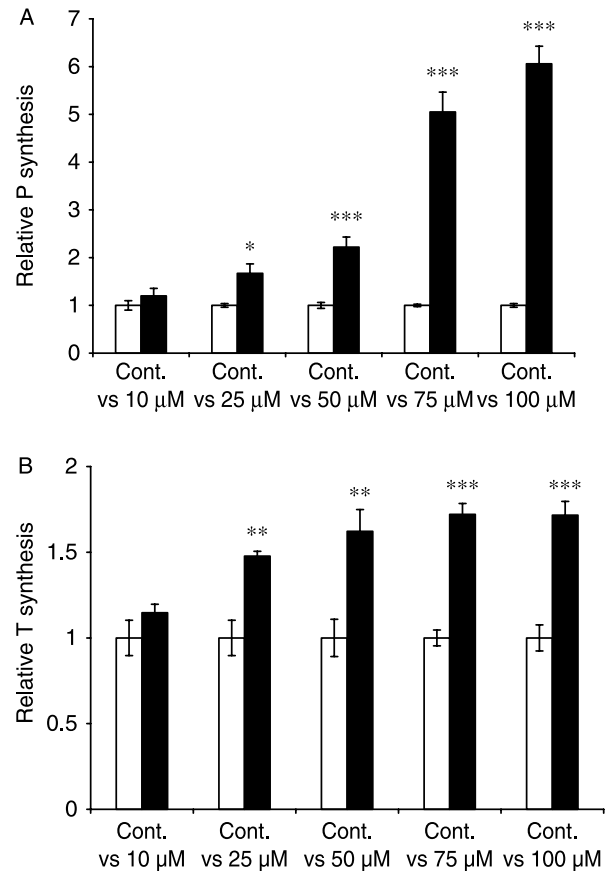

Figure 1 Influence of MEHP on basal (A) progesterone and (B) testosterone syntheses in MLTC- 1 cells ( $n=5-6$ per group). The cells were seeded at a density of $6 \times 10^{4}$ cells in 24-well plates and allowed to adhere overnight. The cells were then exposed to MEHP (dissolved in DMSO), in the concentration range 10-100 $\mu \mathrm{M}$, for $24 \mathrm{~h}$. Control groups were cultured in medium containing the same DMSO concentration as the corresponding exposure group. At the end of exposure, the medium was collected and assayed for steroids. Data are presented as mean \pm s.E.M. ${ }^{*} P<0.05, * * P<0.01$, and ${ }^{* * *} P<0.001$ respectively, versus values for controls.

\section{Lack of effect on CAMP}

Figure 4 shows intracellular cAMP levels in MLTC- 1 and KK-1 cells exposed to $100 \mu \mathrm{M}$ for $1 \mathrm{~h}$. No significant alteration in cAMP levels was observed in either MLTC-1 or KK-1 cells after MEHP exposure. Positive controls,

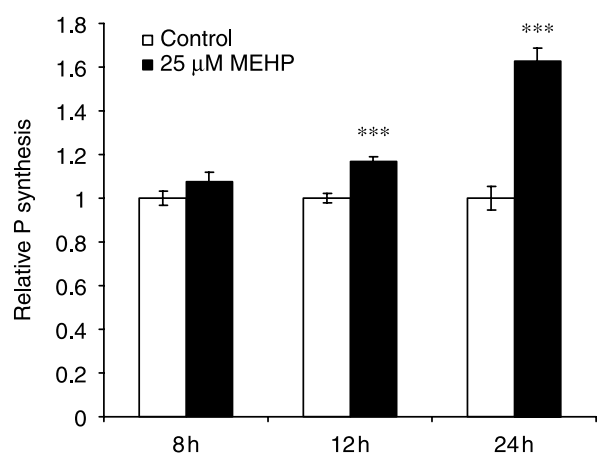

Figure 2 Time-course effect of $25 \mu \mathrm{M}$ MEHP on basal progesterone synthesis in MLTC- 1 cells ( $n=5$ per group). The cells were seeded at a density of $6 \times 10^{4}$ cells in 24-well plates and allowed to adhere overnight. The cells were then treated with either $25 \mu \mathrm{M}$ MEHP or DMSO (control) for 8,12 , or $24 \mathrm{~h}$. At the end of exposure, the medium was collected and used for progesterone analysis. Data are presented as mean \pm s.E.M. ${ }^{* * *} P<0.001$ versus values for controls. 


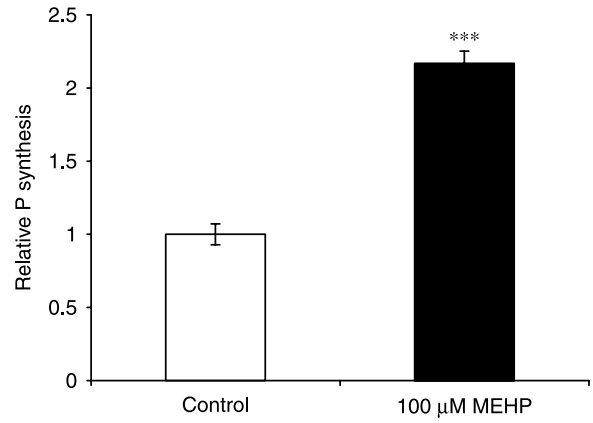

Figure 3 Influence of MEHP on basal progesterone synthesis in KK-1 cells ( $n=5-6$ per group). The cells were seeded at a density of $6 \times 10^{4}$ cells in 24-well plates and allowed to adhere overnight. The cells were then treated with either $100 \mu \mathrm{M}$ MEHP or DMSO (control) for $24 \mathrm{~h}$. At the end of exposure, the medium was collected and used for progesterone analysis. Data are presented as mean \pm S.E.M. ${ }^{* * *} P<0.001$ versus values for controls.

i.e., MLTC- 1 cells treated with $50 \mu \mathrm{g} / \mathrm{l}$ hCG and KK-1 cells treated with $10 \mu \mathrm{M}$ forskolin, exhibited markedly elevated cAMP levels.

\section{Gene expression profiles induced by MEHP and hCG}

To compare the gene expression profile induced by MEHP with the one induced by hCG, mRNA expression of three key steroidogenic proteins was analyzed by rt-Q-RT-PCR. Figure 5A presents the mRNA expression of StAR, p450scc, and p450c17 after MEHP exposure $(100 \mu \mathrm{M}$ for $24 \mathrm{~h})$, whereas the expression of the same
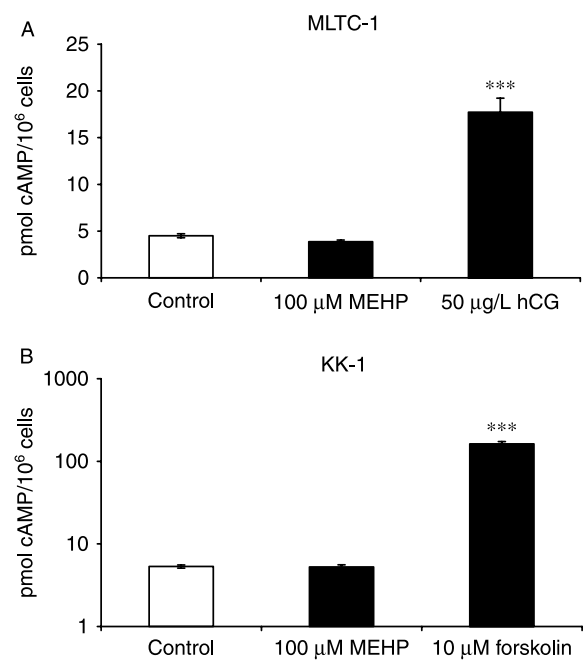

Figure 4 Influence of MEHP on intracellular cAMP levels in (A) MLTC-1 or (B) KK- 1 cells ( $n=6$ per group). The cells were seeded at a density of $6 \times 10^{4}$ cells in 24-well plates and allowed to adhere overnight. The cells were then treated with either $100 \mu \mathrm{MMEHP}$ or DMSO (control), in a medium containing $0.25 \mathrm{mM}$ IBMX, for $1 \mathrm{~h}$. Intracellular cAMP was extracted with $0.1 \mathrm{M} \mathrm{HCl}$ and measured immediately. hCG- and forskolin-treated cells were used as positive controls in the respective experiments. Data are presented as mean \pm S.E.M. ${ }^{* * *} P<0.001$ versus values for controls.
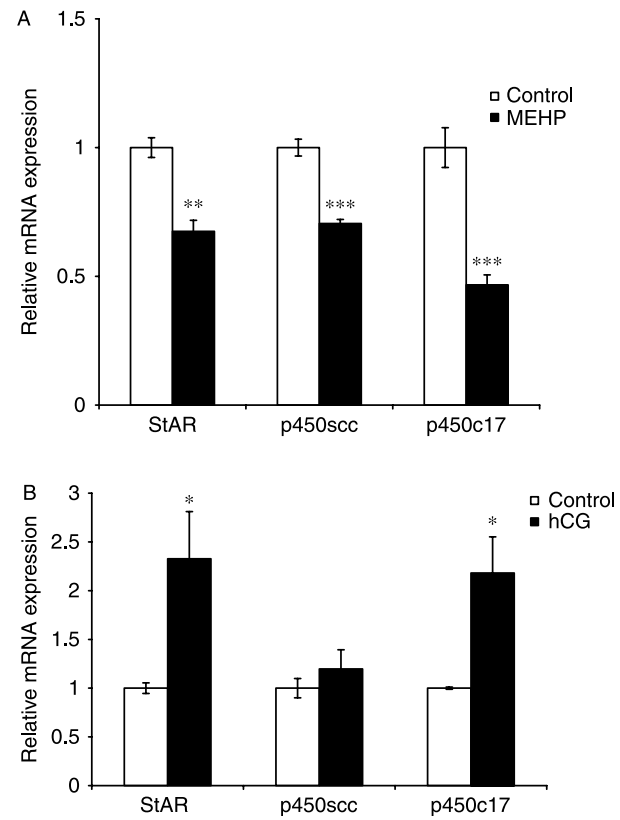

Figure 5 Comparison of MEHP- and hCG-induced changes in mRNA expression of genes involved in steroidogenesis. MLTC-1 cells were seeded at a density of $1 \times 10^{6}$ cells/flask in $160 \mathrm{ml}$ flasks and allowed to adhere overnight. The cells were then treated with either (A) $100 \mu \mathrm{M}$ MEHP $(n=4)$ for $24 \mathrm{~h}$ or (B) $10 \mu \mathrm{g} / \mathrm{hCG}(n=3)$ for $4 \mathrm{~h}$. Total RNA was isolated and $m R N A$ levels determined with real-time quantitative RT PCR (rt-Q-RT-PCR). The mRNA expression of StAR, p450scc, and p450c17 was normalized to $\beta$-actin. Data are presented as mean \pm s.E.M. ${ }^{*} P<0.05$, ${ }^{* *} P<0.01$, and ${ }^{* * *} P<0.001$ respectively, versus values for controls.

genes after hCG treatment $(10 \mu \mathrm{g} / \mathrm{l}$ for $4 \mathrm{~h})$ is shown in Fig 5B. Although MEHP strongly stimulated steroidogenesis, its influence on the analyzed genes differed noticeably from that of hCG. The hCG treatment up-regulated the expression of StAR $(2.3$-fold $)$ and p450c17 (2.2-fold). MEHP exposure reduced the expression of StAR, p450scc, and p450c17 by $\sim 35$, 30 , and $50 \%$ respectively.

\section{Effect of p450scc inhibition}

In order to determine the site of action of MEHP, MLTC-1 cells were exposed to $100 \mu \mathrm{M}$ MEHP for $24 \mathrm{~h}$ in the presence or the absence of a p450scc inhibitor (aminoglutethimide). The cells exposed to $100 \mu \mathrm{M}$ MEHP without aminoglutethimide had a 4.1-fold higher progesterone synthesis than control cells, whereas the progesterone production in cells exposed to $100 \mu \mathrm{M}$ MEHP together with $400 \mu \mathrm{M}$ aminoglutethimide was only 1.9-fold higher than in controls (Table 1). Hence, the primary site of action appears to be prior to the formation of pregnenolone in the mitochondrion. The finding that MEHP stimulated steroidogenesis to some degree also in the presence of aminoglutethimide suggests a second minor site of action, subsequent to pregnenolone formation. 
Table 1 Influence of $100 \mu \mathrm{M}$ mono-(2-ethylhexyl) phthalate (MEHP) on basal progesterone synthesis in the mouse Leydig tumor cell line MLTC1 cells, in the presence or the absence of $400 \mu \mathrm{M}$ aminoglutethimide ( $n=6$ per group).

\begin{tabular}{lccc}
\hline $\begin{array}{l}\text { Progesterone } \\
\text { (pmol } / 10^{6} \text { cells) }\end{array}$ & Control & $\begin{array}{c}\mathbf{1 0 0} \boldsymbol{\mu M} \\
\text { MEHP }\end{array}$ & $\begin{array}{c}\text { Fold change } \\
\text { compared with } \\
\text { controls }\end{array}$ \\
\hline (-) Aminoglutethimide & $73.1 \pm 10.5$ & $300 \pm 23.9^{*}$ & 4.1 \\
(+) Aminoglutethimide & $6.79 \pm 1.43^{+}$ & $12.8 \pm 1.14^{*,+}$ & 1.9 \\
\hline
\end{tabular}

The cells were seeded at a density of $6 \times 10^{4}$ cells in 24-well plates and allowed to adhere overnight. The cells were then treated with either $100 \mu \mathrm{M}$ MEHP or DMSO (control) for $24 \mathrm{~h}$. Aminoglutethimide was added to a final concentration of $400 \mu \mathrm{M}$ in the (+) aminoglutethimide exposure medium. Data are presented as mean \pm S.E.M. The degree of increase after MEHP exposure is indicated in the last column.

* Significantly different $(P<0.001)$ from controls not treated with MEHP. ${ }^{+}$Significantly different $(P<0.001)$ from the corresponding $(-)$ aminoglutethimide group.

\section{Lack of effect on StAR}

The expression of StAR protein in MLTC-1 cells exposed to $100 \mu \mathrm{M}$ MEHP for $24 \mathrm{~h}$ was detected by Western blot (Fig. 6, upper panel). StAR protein expression was quantified with the software Quantity One and normalized to $\beta$-actin (Fig. 6 , lower panel). As can be seen in the figure, MEHP exposure did not change the StAR protein level.

\section{Up-regulation of $\mathrm{HSL}$ and $\mathrm{HMG}-\mathrm{CoA}$ reductase}

Since steroidogenesis is dependent on the amount of available cholesterol, the mRNA expression of hormonesensitive lipase (HSL, Lipe) and 3-hydroxy-3-methylglutaryl coenzyme A (HMG-CoA) reductase $(\mathrm{HmgCr})$ was measured. HSL as well as HMG-CoA reductase was up-regulated in MLTC-1 cells exposed to MEHP (Fig. 7). The lowest concentration of MEHP that resulted in increased expression of HSL (1.9-fold) and HMG-CoA

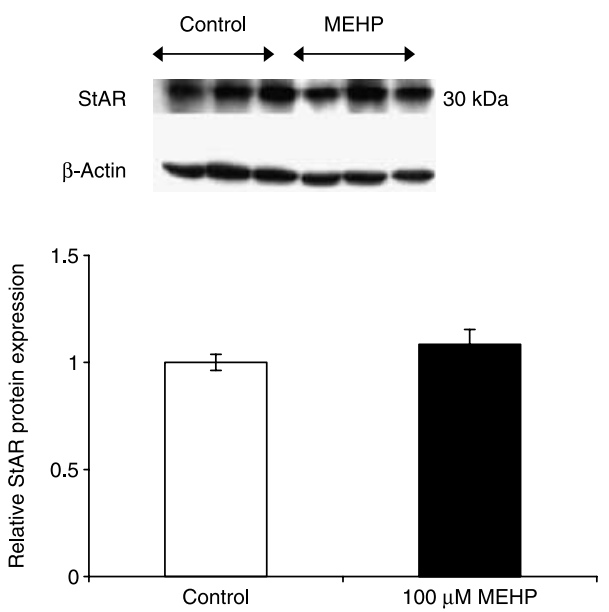

Figure 6 Expression of StAR protein in MLTC-1 cells exposed to $100 \mu \mathrm{M}$ MEHP or DMSO (controls) for $24 \mathrm{~h}$. Ten micrograms of total protein were used to detect StAR protein levels by western blot. StAR protein expression was quantified with the software Quantity One, normalized to $\beta$-actin, and presented as mean \pm S.E.M. (lower panel).
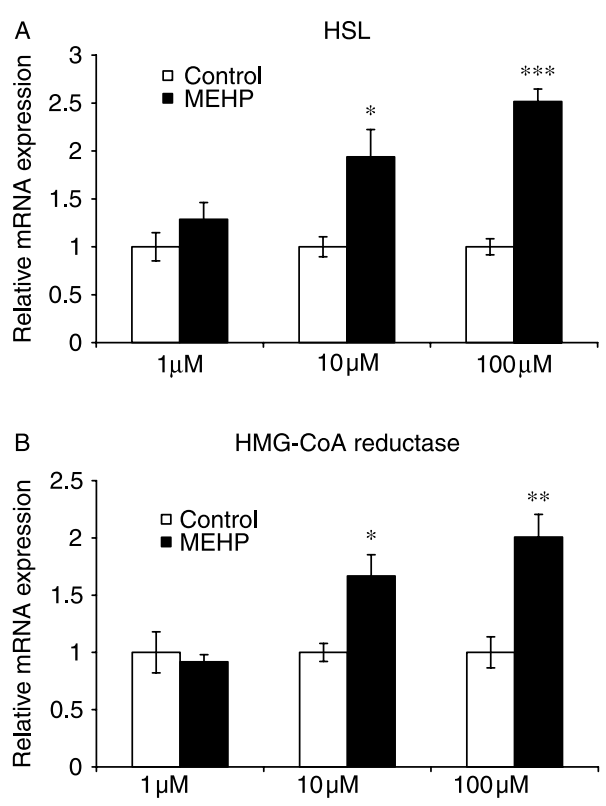

Figure 7 Effects of MEHP on the mRNA expression of (A) hormonesensitive lipase (HSL) and (B) 3-hydroxy-3-methylglutaryl coenzyme A (HMG-CoA) reductase in MLTC-1 cells. The cells were seeded at a density of $7 \times 10^{5}$ cells/flask in $50 \mathrm{ml}$ flasks and allowed to adhere overnight. Thereafter, the cells were exposed to 1-100 $\mu \mathrm{M}$ MEHP $(n=4)$ for $24 \mathrm{~h}$. Total RNA was isolated and mRNA levels determined with real-time quantitative RT PCR (rt-Q-RT-PCR). The mRNA expression of HSL and HMG-CoA reductase was normalized to $\beta$-actin. Data are presented as mean \pm s.E.M. ${ }^{*} P<0.05,{ }^{* *} P<0.01$ and $* * * P<0.001$ respectively, versus values for controls.

reductase (1.7-fold) was $10 \mu \mathrm{M}$. The concentration $100 \mu \mathrm{M}$ had a stronger effect, whereas the lowest concentration $(1 \mu \mathrm{M})$ did not influence the expression of HSL and HMG-CoA reductase.

\section{Inhibition of hCG-induced steroidogenesis}

Progesterone synthesis in MLTC-1 cells exposed to $100 \mu \mathrm{M}$ MEHP and thereafter stimulated with $10 \mu \mathrm{g} / \mathrm{l}$

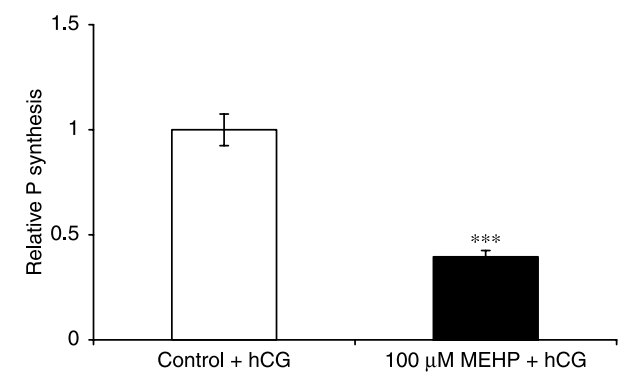

Figure 8 Influence of MEHP on hCG-stimulated progesterone synthesis in MLTC- 1 cells ( $n=4$ per group). The cells were seeded at a density of $1 \times 10^{6}$ cells/flask in $160 \mathrm{ml}$ flasks and allowed to adhere overnight. The cells were then exposed to $100 \mu \mathrm{M}$ MEHP or DMSO (control) for $24 \mathrm{~h}$. At the end of incubation, the medium was aspirated and steroidogenesis induced by hCG-treatment $(10 \mu \mathrm{g} / \mathrm{l})$ for $4 \mathrm{~h}$. Thereafter, the medium was collected and assayed for progesterone. Data are presented as mean \pm S.E.M. ${ }^{* * *} P<0.001$ versus values for controls. 
hCG for $4 \mathrm{~h}$ is shown in Fig. 8. In sharp contrast to its stimulatory effect on basal steroidogenesis, MEHP significantly inhibited hCG-induced progesterone synthesis. Progesterone production was reduced by $\sim 60 \%$ after MEHP exposure, when compared with hCG-stimulated control cells.

\section{Discussion}

This study shows that MEHP can stimulate basal steroidogenesis in gonadal cells of both sexes. We demonstrate that MEHP increases basal steroid synthesis in a concentration-dependent manner by a cAMPindependent mechanism. MEHP was found to stimulate steroidogenesis in Leydig as well as granulosa cells. This is the first article describing a stimulatory effect in female gonadal cells. Gene expression data revealed that an increased amount of cholesterol available for steroidogenesis is the likely underlying mechanism. These findings contribute to the understanding of the reproductive and developmental toxicology of phthalates.

Alterations in steroidogenesis are of great importance since sex hormones regulate fetal development as well as the onset of puberty. Male sexual differentiation and development is critically dependent on Leydig cell testosterone secretion. Disruption of androgen synthesis (or signaling) adversely affects prenatal as well as postnatal sexual development in the male. Complete inactivation of either the luteinizing hormone (LH) receptor (Gromoll et al. 2002) or the androgen receptor (Brown et al. 1990) gives rise to a female phenotype in human XY males. Development of female internal and external genitalia does not require gonadal hormones and thus the female fetus is less vulnerable to in utero exposure. Pubertal development, on the other hand, is dependent on sex hormones in both boys and girls. Female mice overexpressing hCG, thereby producing high progesterone levels, are known to develop precocious puberty and infertility (Rulli et al. 2002). Hence, sex differentiation and development can be affected by increased as well as decreased steroidogenesis.

Recent studies indicate that phthalate exposure can alter steroid hormone-dependent processes in both the male and the female. Swan et al. (2005) discovered reduced anogenital distance and impaired testicular descent in boys of mothers with elevated phthalate exposure during pregnancy. Later in life, pubertal development is tightly regulated by the gonadotropin-releasing hormone pulse generator that stimulates pituitary and gonadal hormone synthesis. Thus, a stimulation of basal steroidogenesis by phthalates may possibly result in precocious puberty. Consistent with this, Colon et al. (2000) found significantly elevated serum levels of DEHP, di- $n$-butyl phthalate (DBP), and MEHP in $68 \%$ of girls in Puerto Rico with premature breast development. In addition to the findings in humans, it is well known that phthalates cause a number of reproductive and developmental disorders in animal models. In the male, intrauterine phthalate exposure affects reproductive tract development in several ways. DEHP and DBP, which also have endocrine disrupting potential, cause hypospadias, cryptorchidism, and malformations of epididymis, prostate, and testes (Mahood et al. 2005, Foster 2006). This TDS-like phenotype appears to be caused by an alteration in fetal testosterone synthesis during a time period when androgens regulate development (Fisher et al. 2003, Foster 2006). A sharp decrease in testicular testosterone production has been shown to precede the abovementioned malformations (Foster 2006). In female mice, DEHP (2 g/kg) decreases estradiol synthesis, prolongs the estrus cycle, and causes anovulation (Davis et al. 1994a). Using cultured granulosa cells, it has been demonstrated that MEHP is the active metabolite in reducing estradiol production (Lovekamp \& Davis 2001). Although the previously mentioned study by Swan et al. (2005) indicates that human developmental disturbances are associated with phthalate exposure, it should be emphasized that no conclusive evidence exists of a relationship between phthalate exposure and TDS in humans.

Previous in vitro studies to determine the mechanisms of action of phthalates have focused on $\mathrm{LH}$ receptormediated steroidogenesis, induced either by hCG or 8-Br-cAMP (Davis et al. 1994b, Dees et al. 2001, Wang et al. 2006). LH is indeed required for postnatal sexual development, but its role in prenatal differentiation has been shown to be less crucial (Ahtiainen et al. 2007). Male fetuses show normal differentiation also in the absence of $\mathrm{LH}$-induced testosterone synthesis (Weiss et al. 1992, El-Gehani et al. 1998, Zhang et al. 2001). In rodents a number of non-gonadotropic factors are able to substitute for $\mathrm{LH}$, whereas in humans hCG is thought to have this role (Ahtiainen et al. 2007). For this reason, alterations in basal steroidogenesis may be as important as the previously described effects on $\mathrm{LH}$ receptor-mediated steroid synthesis. However, since the regulation is likely to differ between species, applying animal data to humans should be done with some caution.

Our finding that MEHP markedly enhances steroid synthesis in Leydig as well as granulosa cells is not congruent with most in utero studies. However, most investigators have used DEHP/DBP doses high enough to ensure a high prevalence of reproductive malformations; most available data are based on high-dose (above $100 \mathrm{mg} / \mathrm{kg}$ per day) exposure (Parks et al. 2000, Shultz et al. 2001). At doses relevant to human exposure, DEHP appears to cause more subtle effects, including enhanced testosterone secretion. Andrade and collaborators recently discovered that in utero and lactational exposure to $0.045 \mathrm{mg} / \mathrm{kg}$ per day DEHP significantly increased serum testosterone concentrations and reduced daily sperm production in the male offspring (Andrade et al. 2006). This dose is equivalent to the daily exposure level of DEHP in Korean women (Koo \& Lee 2005) and only threefold higher than the estimated daily intake in the general German population (Koch et al. 2003). Thus, 
the effects described in this article resemble alterations associated with low-dose rather than high-dose exposure. Interestingly, during the preparation of this article, Ge et al. (2007) established that MEHP stimulates testosterone synthesis in primary rat Leydig cells. It is therefore likely that the mechanistic findings from cell lines presented in this article reflect the situation in primary steroidogenic cells. In addition, Ge et al. (2007) discovered a biphasic effect of DEHP on pubertal development, with low-dose treatment advancing the onset of puberty.

The discovery that phthalates influence testicular function at doses equivalent to the exposure level in the general population is particularly interesting since the incidence of male reproductive disorders is increasing. Hypospadias, cryptorchidism, and testicular cancer have become more frequent during the last 50 years (Bay et al. 2006). At present, genetic as well as environmental factors are believed to be involved in the development of these disorders. In 2004, Boisen et al. (2004) discovered a significantly higher prevalence of cryptorchidism among Danish infants as compared with 40 years earlier, indicating the importance of environmental factors. Genetic factors, on the other hand, appear to play a role in the development of testicular cancer. Black \& Hispanic men are known to have a significantly lower incidence of testicular cancer than white men residing in the same area (Spitz et al. 1986). However, it should be emphasized that extrapolating in vitro and in vivo data to humans must be done with caution. Instead, mechanisms discovered in animal models should serve as hypotheses for future research.

Data from rt-Q-RT-PCR in MLTC-1 cells are in agreement with our finding that the stimulation of steroidogenesis occurs independently of cAMP. Among the proteins involved in steroidogenesis, StAR and p450c17 appears to be the ones most tightly regulated by cAMP. Anakwe \& Payne (1987) demonstrated that removal of cAMP from the culture medium totally abolished the synthesis of p450c17 in mouse Leydig cells after $48 \mathrm{~h}$. StAR, which mediates the rate-limiting step in steroidogenesis, is acutely regulated in adrenal as well as gonadal steroidogenic cells through cAMPmediated signaling (Manna et al. 2003). In our study hCG alone significantly increased, as expected, the mRNA expression of StAR and p450c17. MEHP exposure, on the other hand, resulted in significantly reduced StAR and p450c17 mRNA levels. In contrast to StAR and p450c17, the synthesis and activity of p450scc and $3 \beta$-hydroxysteroid dehydrogenase $(3 \beta \mathrm{HSD})$ remain largely unaffected by cAMP withdrawal (Wing et al. 1984, Anakwe \& Payne 1987). We found that MEHP exposure caused a significant decrement of p450scc mRNA expression. In conclusion, the mRNA expression profiles differ markedly between hCG- and MEHPtreated cells.
Since the analyzed genes in the steroidogenic pathway were down-regulated after MEHP exposure, it is reasonable to believe that MEHP exerted its stimulatory effect primarily through other mechanisms. The unaffected CAMP levels together with the severely reduced stimulation of progesterone production after treatment with a p450scc inhibitor (aminoglutethimide) suggest a site of action subsequent to CAMP but prior to pregnenolone formation. An earlier study described increased StAR mRNA and protein expressions after MBP exposure (Wang et al. 2006). Our data, on the other hand, do not support a role for StAR in the stimulation of steroidogenesis. Another possible mechanism is activation of protein kinase $C$ (PKC), which has been shown to enhance basal steroid synthesis (Brunswig et al. 1986, Nikula \& Huhtaniemi 1989) but has an opposite effect on hCG-stimulated synthesis (Benhaim et al. 1987). These effects resemble those seen after MEHP exposure in our study. However, co-treatment with a PKC inhibitor (GF109203X) did not reduce the stimulatory effect of MEHP (data not shown), thus excluding PKC activation as the underlying mechanism.

The time course of stimulation of progesterone synthesis together with the lack of effect on second messenger signaling indicates that altered gene expression underlies the effect of MEHP on steroidogenesis. Sex steroid synthesis depends not only on steroidogenic enzymes and transport proteins, but also on cholesterol availability. In this study, MEHP up-regulated two genes involved in cholesterol metabolism and mobilization, HSL (Lipe), and HMG-CoA reductase $(\mathrm{HmgCr})$. An elevated expression of HSL and HMG-CoA reductase was detected after exposure to 10 and $100 \mu \mathrm{M}$, but not $1 \mu \mathrm{M}$, MEHP. Hence, these genes were up-regulated at MEHP concentrations that increased steroidogenesis. HSL is a widely distributed enzyme with the capacity to hydrolyze several lipid substrates, including triacylglycerols and cholesteryl esters, whereas HMG-CoA reductase is the rate-limiting enzyme in cholesterol synthesis (Yeaman 2004). These enzymatic activities are important for testosterone synthesis, and reduced hydrolysis of cholesteryl esters as well as decreased HMG-CoA reductase activity has been associated with decreased steroidogenesis in the aging rat testis (Liao et al. 1993). In contrast, Leydig cells with a high testosterone production display high HMG-CoA reductase activity and strong $\mathrm{HSL}$ expression (Hou et al. 1990, Rao et al. 2003). In steroidogenic cells HSL hydrolyzes cholesteryl esters to free cholesterol that is subsequently transported into the mitochondria for further conversion to pregnenolone (Rao et al. 2003). As shown by Rao et al. (2003), rodent Leydig cell lines with a high level of steroid synthesis show strong $H S L$ expression, whereas HSL is only weakly expressed in cells with a low level of synthesis. From guinea pigs it is known that HSL expression and enzymatic activity are positively correlated with serum testosterone concentrations (Kabbaj et al. 2001). HMG-CoA reductase catalyzes the conversion of HMG-CoA to mevalonate, 
which is considered to be the major point of regulation in the synthesis of cholesterol. In Leydig as well as granulosa cells, hCG/cAMP treatment enhances HMG-CoA reductase activity and causes a concomitant increase in steroid production (Hou et al. 1990, Medicherla et al. 1996).

The relative importance of cholesterol mobilization, intracellular synthesis, and uptake varies between different steroidogenic cells. Leydig cell steroidogenesis appears to rely primarily on hydrolysis of cholesteryl esters and endogenous cholesterol synthesis, whereas adrenal cells are highly dependent on lipoprotein uptake (Travert et al. 2000). However, Leydig cells also have the capacity for lipoprotein uptake and if testosterone synthesis is blocked by a HMG-CoA reductase inhibitor, addition of HDL fully overcomes the inhibitory effect (Travert et al. 2000). The flexibility to use different mechanisms to increase the amount of cholesterol available for steroid synthesis may also explain why testosterone production was found to be normal in HSL-/- mice (Osuga et al. 2000). To conclude, our results strongly suggest that MEHP stimulates steroidogenesis by increasing the amount of cholesterol available for steroid biosynthesis. The complexity of cholesterol metabolism in steroidogenic cells implies that future studies should investigate in more detail the respective role of cholesterol synthesis, mobilization, and transport in MEHP-induced stimulation of steroidogenesis.

In this study, the mechanism whereby MEHP upregulates $H S L$ and HMG-CoA reductase was not established. However, it is known that MEHP and a number of other industrial chemicals activate peroxisome proliferator-activated receptors (PPARs). PPARs belong to the nuclear hormone receptor superfamily and regulate, by binding to target gene peroxisome proliferator response elements, a wide range of genes involved in lipid metabolism (Maloney \& Waxman 1999, Le Jossic-Corcos et al. 2004, Feige et al. 2007). Of the three known isoforms, PPAR $\alpha$, PPAR $\beta$, and PPAR $\gamma$, MEHP has been found to activate the $\alpha$ and $\gamma$ isoforms (Venkata et al. 2006). Both these isoforms are expressed in Leydig as well as granulosa cells, and MEHP-induced activation of these transcription factors may explain the increased HSL and HMG-CoA reductase expression found in this study (Schultz et al. 1999, Lovekamp-Swan et al. 2003, Borch et al. 2006). The PPAR $\alpha$ activation has been related to increased HMG-CoA reductase mRNA expression and cholesterogenesis, whereas the activation of PPAR $\gamma$ increases the expression of HSL (Le Jossic-Corcos et al. 2004, Feige et al. 2007). In favor of this hypothesis, known PPAR $\gamma$ ligands increase granulosa cell progesterone synthesis by a mechanism described to be independent of p450scc and 33HSD (Froment et al. 2003). The effects of MEHP exposure on the liver and ovary have been attributed to PPAR activation (Lovekamp-Swan et al. 2003, Corton \& Lapinskas 2005, Lapinskas et al. 2005), but the role of PPAR signaling in testicular toxicity is not that clear.
Studies of PPAR $\alpha$ null mice have revealed that some but not all testicular effects seen after DEHP exposure is due to PPAR $\alpha$ activation (Ward et al. 1998), whereas the role of PPAR $\gamma$ has not yet been properly evaluated. MEHP acting as a PPAR ligand may also explain why this phthalate reduced steroid synthesis under hCG-induced conditions. PPAR $\gamma$ ligands have been shown to interfere with cAMP signaling by inhibiting the phosporylation of cAMP-activated transcription factors and their binding to the DNA. Han et al. (2005) discovered that PPAR $\gamma$ ligands reduced the DNA-binding activities of cAMP response element-binding protein (CREB) and Sp1, both of which are crucial for the transcriptional regulation of steroidogenic genes. Transcription factors CREB and Sp1 positively regulate StAR, p450scc, and p450c17, all of which were down-regulated by MEHP in this study (Lund et al. 1990, Venepally \& Waterman 1995, Manna et al. 2003, Zhang \& Veldhuis 2004, Sher et al. 2007).

Hence, activation of PPAR may be the mechanism underlying the opposite effects of MEHP on steroidogenesis. According to this hypothesis, MEHP stimulates basal steroidogenesis by activating transcription factors belonging to the PPAR family. PPAR activation induces the expression of genes involved in cholesterol metabolism, thereby increasing the substrate for steroid synthesis. On the other hand, the activation of PPAR transcription factors also alters the DNA-binding capacity of cAMP-activated transcription factors causing a down-regulation of steroidogenic genes. As a consequence, the stimulatory effect of hCG is reduced in MEHP-exposed cells. Further experiments should be designed to test this hypothesis.

Since it is difficult to state from in vitro and in vivo animal data, future studies should address whether phthalate exposure is correlated with the increased frequency of reproductive disorders in the human population. Environmental factors have been suggested to influence the risk of precocious puberty (Teilmann etal. 2006), and to assess the impact of phthalate-stimulated steroidogenesis is an important task. In view of the fact that phthalates can both stimulate steroidogenesis in the male and female gonadal cells (this study) and inhibit gonadotropin-induced steroidogenesis, phthalate research should be expanded to include work on other hormones of importance for male sexual development.

\section{Materials and Methods}

\section{Cell culture}

The mouse Leydig tumor cell line (MLTC-1) was purchased from American Type Culture Collection (Rockville, MD, USA), whereas the granulosa tumor cell line, KK-1, was a generous gift from Dr Ilpo Huhtaniemi (Imperial College, London). MLTC-1 cells were maintained in Waymouth's medium supplemented with $4.5 \%$ heat-inactivated fetal bovine serum (Sigma) and 9\% heat-inactivated horse serum (Sigma), 
containing $0.1 \mathrm{~g} / \mathrm{l}$ gentamycin (Gibco). KK-1 cells were maintained in DMEM supplemented with $10 \%$ heat-inactivated fetal bovine serum (Sigma), containing 100000 units/I penicillin and $0.1 \mathrm{~g} / \mathrm{l}$ streptomycin (Sigma). The cells were cultured at $37{ }^{\circ} \mathrm{C}$ in a humidified atmosphere of $5 \% \mathrm{CO}_{2}$ and $95 \%$ air. Both cell types have a functional steroidogenic pathway, but in contrast to MLTC-1 cells, KK-1 cells (in the passages used) lack $\mathrm{LH}$ receptors and thus do not respond to hCG or LH. Due to a reduced p450c17 activity, MLTC-1 cells produce more progesterone than Leydig cells normally do. For this reason, progesterone as well as testosterone was measured. Depending on exposure time, control MLTC- 1 cells had a basal progesterone and testosterone synthesis of $\sim 100$ 200 pmol $/ 10^{6}$ cells, whereas control KK-1 cells had a basal progesterone synthesis of $\sim 30 \mathrm{pmol} / 10^{6}$ cells. Under hCGinduced conditions, MLTC- 1 cells produced $\sim 6.5 \mathrm{nmol}$ progesterone $/ 10^{6}$ cells.

\section{MEHP exposure}

MEHP (TCl, Zwijndrecht, Belgium) was dissolved in dimethyl sulfoxide (DMSO). The final concentration of DMSO did not exceed $0.05 \%$ in any exposure medium. In all experiments, control cells were cultured in medium containing the same concentration of DMSO as the corresponding MEHP exposure medium. In the time-course experiment, separate controls were used for each time point. All exposure media were prepared using either serum-free Waymouth's medium or serum-free DMEM containing $0.1 \%$ BSA. The duration of exposure varied from 1 to $24 \mathrm{~h}$ for the different analyses and is stated in the description of each measurement below.

\section{Progesterone and testosterone measurements}

To measure progesterone and testosterone production, the cells were seeded at a density of $6 \times 10^{4}$ cells in 24 -well plates and allowed to adhere overnight. The cells were then exposed to MEHP, in the concentration range 10-100 $\mu \mathrm{M}$, for $24 \mathrm{~h}$. In the time-course experiment MLTC-1 cells were exposed to $25 \mu \mathrm{M}$ MEHP for 8, 12, or $24 \mathrm{~h}$. To evaluate the influence of a p450scc inhibitor, aminoglutethimide (Sigma) was added to a final concentration of $400 \mu \mathrm{M}$ in one of the experiments. In one experiment, steroidogenesis was stimulated with $10 \mu \mathrm{g} / \mathrm{l}$ hCG for $4 \mathrm{~h}$. At the end of exposure, the media were collected and used for the determination of hormone content. Progesterone and testosterone concentrations were determined by timeresolved fluoroimmunoassay, using commercially available DELFIA Progesterone and Testosterone kits (Perkin-Elmer, Upplands Väsby, Sweden) respectively. The hCG-stimulated progesterone synthesis was determined in the same way, with the exception that cells were cultured in $160 \mathrm{ml}$ flasks.

\section{cAMP analyses}

To measure intracellular cAMP levels, cells were seeded at a density of $6 \times 10^{4}$ cells/well in 24-well plates and allowed to adhere overnight. The cells were then incubated for $60 \mathrm{~min}$ in a medium containing $0.25 \mathrm{mM}$ 3-Isobutyl-1-methylxanthine together with MEHP. The cells treated with either $50 \mu \mathrm{g} / \mathrm{l}$
hCG (MLTC-1) or $10 \mu \mathrm{M}$ forskolin (KK-1) were used as positive controls. At the end of incubation, the media were removed and intracellular cAMP was extracted with $0.1 \mathrm{M} \mathrm{HCl}$ at $4{ }^{\circ} \mathrm{C}$ for $45 \mathrm{~min}$. Immediately thereafter, aliquots of the samples were acetylated by adding $3 \mu \mathrm{l}$ freshly prepared mixture of triethylamine and acetic anhydride $(2: 1)$ to $20 \mu \mathrm{l}$ samples. The cAMP concentrations were assayed the same day by timeresolved fluoroimmunoassay, using a commercially available cAMP kit (Perkin-Elmer).

\section{Western blot analysis of 30 kDa StAR}

MLTC- 1 cells were seeded at a density of $1 \times 10^{6}$ cells $/ 160 \mathrm{ml}$ flask and allowed to adhere overnight. The cells were then exposed to $100 \mu \mathrm{M}$ MEHP for $24 \mathrm{~h}$. At the end of exposure, the cells were trypsinized, resuspended in Waymouth's medium supplemented with $0.1 \% \mathrm{BSA}$, and pelleted by centrifugation at $400 \mathrm{~g}$ for $10 \mathrm{~min}$. The cell pellets were placed at $-20{ }^{\circ} \mathrm{C}$ for $60 \mathrm{~min}$. Thereafter, the cells were lysed by sonication on ice for $20 \mathrm{~min}$ in $50 \mu \mathrm{l}$ ARF lysis buffer (50 mM HEPES pH 7.5, $150 \mathrm{mM}$ $\mathrm{NaCl}, 1 \mathrm{mM}$ EDTA, $2.5 \mathrm{mM}$ EGTA, 0.1\% Tween-20 before use supplemented with $100 \mathrm{mM}$ phenylmethylsulphonyl fluoride, $1 \mathrm{M} \beta$-glycerophosphate, $0.4 \mathrm{M} \mathrm{NaF}, 100 \mathrm{mM} \mathrm{NaVO}_{4}$, and 1 tablet of 'Roche' Mini Complete). Lysates were centrifuged at $20000 \mathrm{~g}$ for $10 \mathrm{~min}$ at $4{ }^{\circ} \mathrm{C}$ and supernatants were stored at $-80^{\circ} \mathrm{C}$ until analysis.

The protein content of supernatants was determined using the method of Bradford (1976). From each sample $10 \mu \mathrm{g}$ protein were solubilized in loading buffer $(65 \mathrm{mM}$ Tris- $\mathrm{HCl}, \mathrm{pH}$ $6.8,5 \%$ SDS, $5 \% \quad \beta$-mercaptoethanol, $10 \%$ glycerol, and $0.01 \%$ bromphenol blue) and separated on a $12 \%$ SDS-PAGE minigel (Mini Protean II, Bio-Rad). Proteins were thereafter electrophoretically transferred overnight to a polyvinyl difluoride (PVDF) membrane (Bio-Rad) using a transfer buffer containing $25 \mathrm{mM}$ Tris, $192 \mathrm{mM}$ glycine, and 20\% methanol. The membrane was washed three times (5 min each) in distilled water and preincubated in Tris-buffered saline (TBS) with $0.1 \%$ Tween-20 and 5\% non-fat dried milk for $2 \mathrm{~h}$. The membrane was then incubated for $1 \mathrm{~h}$ with rabbit anti-mouse StAR antibody, generated against a glutathione $S$-transferase fusion protein from full-length StAR cDNA (Hales et al. 2000). The PVDF membrane was washed three times (15 min each) in TBS with $0.5 \%$ Tween-20, followed by three washes (15 min each) in TBS with $0.1 \%$ Tween-20 (TBST). The membrane was then incubated for $1 \mathrm{~h}$ with the secondary antibody, donkey antirabbit IgG conjugated with horseradish peroxidase (HRP; Amersham Biosciences) diluted in TBST. The membrane was then washed as described previously. $\beta$-Actin was used as an internal control and a HRP-conjugated $\beta$-actin antibody (cat nr: ab20272, Abcam, Cambridge, UK) was used to measure its expression. The specific signal was revealed using Immobilon Western HRP Substrate Peroxide Solution (Millipore Corporation, Bedford, MA, USA), according to the manufacturer's description. Finally, the membranes were exposed to a highperformance autoradiography film (Amersham Biosciences). Autoradiograms were quantified using the software Quantity One (Bio-Rad) and StAR protein expression was normalized to $\beta$-actin. 


\section{Isolation of total $R N A$ and real-time quantitative $R T$ PCR (rt-Q-RT-PCR)}

MLTC- 1 cells were seeded at a density $1 \times 10^{6}$ cells $/ 160 \mathrm{ml}$ flask or $7 \times 10^{5}$ cells $/ 50 \mathrm{ml}$ flask (depending on experiment) and exposed to 1-100 $\mu \mathrm{M}$ MEHP (depending on experiment) for $24 \mathrm{~h}$. Total RNA was isolated using TRIzol LS Reagent (Invitrogen) according to the manufacturer's description and resuspended in $10 \mathrm{mM}$ Tris- $\mathrm{HCl}, \mathrm{pH}$ 8.0. RNA concentrations were determined spectrophotometrically and $50 \mathrm{ng}$ was used for rt-Q-RT-PCR. Sequences were obtained from Ensembl Genome Browser and primers for StAR, p450scc, p450c17, HSL (Lipe), HMG-CoA reductase $(\mathrm{HmgCr})$, and $\beta$-actin were ordered from DNA Technology (Aarhus, Denmark). In order to avoid amplification of genomic DNA, the primers were designed to be intron spanning. Primer sequences are available upon request. rt-Q-RT-PCR was carried out with iScript OneStep RT-PCR kit with SYBR GREEN (Bio-Rad). Melt curves were inspected to ensure that one single product had been amplified in each reaction. mRNA expression of StAR, p450scc, p450c17, $H S L$, and HMG-CoA reductase was normalized to $\beta$-actin. To determine which genes are induced by cAMP signaling in MLTC-1 cells, expression levels of StAR, p450scc, and p450c17 were measured in cells stimulated with hCG for $4 \mathrm{~h}$.

\section{Statistical analyses}

Statistical differences between groups were determined using a two-tailed unpaired Student's $t$-test. Data are presented as mean \pm S.E.M.

\section{Acknowledgements}

We sincerely thank Dr Ilpo Huhtaniemi (Imperial College, London, UK) and Dr Dale Buchanan Hales (University of Illinois at Chicago, Chicago, USA) for their generous gifts of KK-1 cells and StAR antibody respectively. This study was supported by the Faculty of Medicine and the Faculty of Science and Technology, Umeå University, Umeå, Sweden. The authors declare that there is no conflict of interest that would prejudice the impartiality of this scientific work.

\section{References}

Ahtiainen P, Rulli S, Pakarainen T, Zhang FP, Poutanen M \& Huhtaniemi I 2007 Phenotypic characterisation of mice with exaggerated and missing LH/hCG action. Molecular and Cellular Endocrinology 260-262 255-263.

Anakwe OO \& Payne AH 1987 Noncoordinate regulation of de novo synthesis of cytochrome P-450 cholesterol side-chain cleavage and cytochrome P-450 17 alpha-hydroxylase/C17-20 lyase in mouse Leydig cell cultures: relation to steroid production. Molecular Endocrinology 1 595-603.

Andrade AJ, Grande SW, Talsness CE, Gericke C, Grote K, Golombiewski A, Sterner-Kock A \& Chahoud I 2006 A dose response study following in utero and lactational exposure to di-(2-ethylhexyl) phthalate (DEHP): reproductive effects on adult male offspring rats. Toxicology 228 85-97.

Bay K, Asklund C, Skakkebaek NE \& Andersson AM 2006 Testicular dysgenesis syndrome: possible role of endocrine disrupters. Best Practice and Research. Clinical Endocrinology and Metabolism 20 77-90.

Benhaim A, Herrou M, Mittre H \& Leymarie P 1987 Effects of phorbol esters on steroidogenesis in small bovine luteal cells. FEBS Letters 223 321-326.
Boisen KA, Kaleva M, Main KM, Virtanen HE, Haavisto AM, Schmidt IM, Chellakooty M, Damgaard IN, Mau C, Reunanen M et al. 2004 Difference in prevalence of congenital cryptorchidism in infants between two Nordic countries. Lancet 363 1264-1269.

Borch J, Metzdorff SB, Vinggaard AM, Brokken L \& Dalgaard M 2006 Mechanisms underlying the anti-androgenic effects of diethylhexyl phthalate in fetal rat testis. Toxicology 223 144-155.

Bradford MM 1976 A rapid and sensitive method for the quantitation of microgram quantities of protein utilizing the principle of protein-dye binding. Analytical Biochemistry 72 248-254.

Brown TR, Lubahn DB, Wilson EM, French FS, Migeon CJ \& Corden JL 1990 Functional characterization of naturally occurring mutant androgen receptors from subjects with complete androgen insensitivity. Molecular Endocrinology 4 1759-1772.

Brunswig B, Mukhopadhyay AK, Budnik LT, Bohnet HG \& Leidenberger FA 1986 Phorbol ester stimulates progesterone production by isolated bovine luteal cells. Endocrinology 118 743-749.

Colon I, Caro D, Bourdony CJ \& Rosario O 2000 Identification of phthalate esters in the serum of young Puerto Rican girls with premature breast development. Environmental Health Perspectives 108 895-900.

Corton JC \& Lapinskas PJ 2005 Peroxisome proliferator-activated receptors: mediators of phthalate ester-induced effects in the male reproductive tract? Toxicological Sciences 83 4-17.

Davis BJ, Maronpot RR \& Heindel JJ 1994a Di-(2-ethylhexyl) phthalate suppresses estradiol and ovulation in cycling rats. Toxicology and Applied Pharmacology 128 216-223.

Davis BJ, Weaver R, Gaines LJ \& Heindel JJ 1994b Mono-(2-ethylhexyl) phthalate suppresses estradiol production independent of FSH-cAMP stimulation in rat granulosa cells. Toxicology and Applied Pharmacology 128 224-228.

Dees JH, Gazouli M \& Papadopoulos V 2001 Effect of mono-ethylhexyl phthalate on MA-10 Leydig tumor cells. Reproductive Toxicology 15 171-187.

El-Gehani F, Zhang FP, Pakarinen P, Rannikko A \& Huhtaniemi I 1998 Gonadotropin-independent regulation of steroidogenesis in the fetal rat testis. Biology of Reproduction 58 116-123.

Feige JN, Gelman L, Rossi D, Zoete V, Metivier R, Tudor C, Anghel SI, Grosdidier A, Lathion C, Engelborghs Y et al. 2007 The endocrine disruptor monoethyl-hexyl-phthalate is a selective peroxisome proliferator-activated receptor gamma modulator that promotes adipogenesis. Journal of Biological Chemistry 282 19152-19166.

Fisher JS, Macpherson S, Marchetti N \& Sharpe RM 2003 Human 'testicular dysgenesis syndrome': a possible model using in utero exposure of the rat to dibutyl phthalate. Human Reproduction 18 1383-1394.

Foster PM 2006 Disruption of reproductive development in male rat offspring following in utero exposure to phthalate esters. International Journal of Andrology 29 140-147 (discussion 181-145).

Froment P, Fabre S, Dupont J, Pisselet C, Chesneau D, Staels B \& Monget P 2003 Expression and functional role of peroxisome proliferator-activated receptor-gamma in ovarian folliculogenesis in the sheep. Biology of Reproduction 69 1665-1674.

Ge RS, Chen GR, Dong Q, Akingbemi B, Sottas CM, Santos M, Sealfon SC, Bernard DJ \& Hardy MP 2007 Biphasic effects of postnatal exposure to diethylhexylphthalate on the timing of puberty in male rats. Journal of Andrology 28 513-520.

Gromoll J, Schulz A, Borta H, Gudermann T, Teerds KJ, Greschniok A, Nieschlag E \& Seif FJ 2002 Homozygous mutation within the conserved Ala-Phe-Asn-Glu-Thr motif of exon 7 of the LH receptor causes male pseudohermaphroditism. European Journal of Endocrinology 147 597-608.

Hales KH, Diemer T, Ginde S, Shankar BK, Roberts M, Bosmann HB \& Hales DB 2000 Diametric effects of bacterial endotoxin lipopolysaccharide on adrenal and Leydig cell steroidogenic acute regulatory protein. Endocrinology 141 4000-4012.

Han S, Ritzenthaler JD, Rivera HN \& Roman J 2005 Peroxisome proliferator-activated receptor-gamma ligands suppress fibronectin gene expression in human lung carcinoma cells: involvement of both CRE and Sp1. American Journal of Physiology. Lung Cellular and Molecular Physiology 289 L419-L428.

Hou JW, Collins DC \& Schleicher RL 1990 Sources of cholesterol for testosterone biosynthesis in murine Leydig cells. Endocrinology 127 2047-2055. 
Le Jossic-Corcos C, Duclos S, Ramirez LC, Zaghini I, Chevillard G, Martin P, Pineau T \& Bournot P 2004 Effects of peroxisome proliferatoractivated receptor alpha activation on pathways contributing to cholesterol homeostasis in rat hepatocytes. Biochimica et Biophysica Acta 1683 49-58.

Kabbaj O, Holm C, Vitale ML \& Pelletier RM 2001 Expression, activity, and subcellular localization of testicular hormone-sensitive lipase during postnatal development in the guinea pig. Biology of Reproduction $\mathbf{6 5}$ 601-612.

Kato K, Silva MJ, Reidy JA, Hurtz D III, Malek NA, Needham LL, Nakazawa H, Barr DB \& Calafat AM 2004 Mono(2-ethyl-5-hydroxyhexyl) phthalate and mono-(2-ethyl-5-oxohexyl) phthalate as biomarkers for human exposure assessment to di-(2-ethylhexyl) phthalate. Environmental Health Perspectives 112 327-330.

Koch HM, Drexler H \& Angerer J 2003 An estimation of the daily intake of di(2-ethylhexyl)phthalate (DEHP) and other phthalates in the general population. International Journal of Hygiene and Environmental Health 206 77-83.

Koch HM, Preuss R \& Angerer J 2006 Di(2-ethylhexyl)phthalate (DEHP): human metabolism and internal exposure- an update and latest results. International Journal of Andrology 29 155-165 (discussion 181-185).

Koo HJ \& Lee BM 2005 Human monitoring of phthalates and risk assessment. Journal of Toxicology and Environmental Health. Part A 68 1379-1392.

Lapinskas PJ, Brown S, Leesnitzer LM, Blanchard S, Swanson C, Cattley RC \& Corton JC 2005 Role of PPARalpha in mediating the effects of phthalates and metabolites in the liver. Toxicology 207 149-163.

Liao C, Reaven E \& Azhar S 1993 Age-related decline in the steroidogenic capacity of isolated rat Leydig cells: a defect in cholesterol mobilization and processing. Journal of Steroid Biochemistry and Molecular Biology 46 39-47.

Ljungvall K, Tienpont B, David F, Magnusson U \& Torneke K 2004 Kinetics of orally administered di(2-ethylhexyl) phthalate and its metabolite, mono(2-ethylhexyl) phthalate, in male pigs. Archives of Toxicology 78 384-389.

Lottrup G, Andersson AM, Leffers H, Mortensen GK, Toppari J, Skakkebaek NE \& Main KM 2006 Possible impact of phthalates on infant reproductive health. International Journal of Andrology 29 172-180 (discussion 181-175).

Lovekamp TN \& Davis BJ 2001 Mono-(2-ethylhexyl) phthalate suppresses aromatase transcript levels and estradiol production in cultured rat granulosa cells. Toxicology and Applied Pharmacology 172 217-224.

Lovekamp-Swan T, Jetten AM \& Davis BJ 2003 Dual activation of PPARalpha and PPARgamma by mono-(2-ethylhexyl) phthalate in rat ovarian granulosa cells. Molecular and Cellular Endocrinology 201 133-141.

Lund J, Ahlgren R, Wu DH, Kagimoto M, Simpson ER \& Waterman MR 1990 Transcriptional regulation of the bovine CYP17 (P-450(17)alpha) gene. Identification of two CAMP regulatory regions lacking the consensus cAMP-responsive element (CRE). Journal of Biological Chemistry 265 3304-3312.

Mahood IK, Hallmark N, McKinnell C, Walker M, Fisher JS \& Sharpe RM 2005 Abnormal Leydig cell aggregation in the fetal testis of rats exposed to di ( $n$-butyl) phthalate and its possible role in testicular dysgenesis. Endocrinology 146 613-623.

Maloney EK \& Waxman DJ 1999 Trans-activation of PPARalpha and PPARgamma by structurally diverse environmental chemicals. Toxicology and Applied Pharmacology $161209-218$.

Manna PR, Wang XJ \& Stocco DM 2003 Involvement of multiple transcription factors in the regulation of steroidogenic acute regulatory protein gene expression. Steroids 68 1125-1134.

Medicherla S, Azhar S, Cooper A \& Reaven E 1996 Regulation of cholesterol responsive genes in ovary cells: impact of cholesterol delivery systems. Biochemistry 35 6243-6250.

Nikula H \& Huhtaniemi I 1989 Effects of protein kinase C activation on cyclic AMP and testosterone production of rat Leydig cells in vitro. Acta Endocrinologica 121 327-333.

Osuga J, Ishibashi S, Oka T, Yagyu H, Tozawa R, Fujimoto A, Shionoiri F, Yahagi N, Kraemer FB, Tsutsumi $\mathbf{O}$ et al. 2000 Targeted disruption of hormone-sensitive lipase results in male sterility and adipocyte hypertrophy, but not in obesity. PNAS 97 787-792.
Parks LG, Ostby JS, Lambright CR, Abbott BD, Klinefelter GR, Barlow NJ \& Gray LE Jr 2000 The plasticizer diethylhexyl phthalate induces malformations by decreasing fetal testosterone synthesis during sexual differentiation in the male rat. Toxicological Sciences 58 339-349.

Rao RM, Jo Y, Leers-Sucheta S, Bose HS, Miller WL, Azhar S \& Stocco DM 2003 Differential regulation of steroid hormone biosynthesis in R2C and MA-10 Leydig tumor cells: role of SR-B1-mediated selective cholesteryl ester transport. Biology of Reproduction 68 114-121.

Rhodes C, Orton TC, Pratt IS, Batten PL, Bratt H, Jackson SJ \& Elcombe CR 1986 Comparative pharmacokinetics and subacute toxicity of di(2ethylhexyl) phthalate (DEHP) in rats and marmosets: extrapolation of effects in rodents to man. Environmental Health Perspectives 65 299-307.

Rulli SB, Kuorelahti A, Karaer O, Pelliniemi LJ, Poutanen M \& Huhtaniemi I 2002 Reproductive disturbances, pituitary lactotrope adenomas, and mammary gland tumors in transgenic female mice producing high levels of human chorionic gonadotropin. Endocrinology 143 4084-4095.

Schultz R, Yan W, Toppari J, VolkI A, Gustafsson JA \& Pelto-Huikko M 1999 Expression of peroxisome proliferator-activated receptor alpha messenger ribonucleic acid and protein in human and rat testis. Endocrinology $1402968-2975$.

Shea KM 2003 Pediatric exposure and potential toxicity of phthalate plasticizers. Pediatrics 111 1467-1474.

Sher N, Yivgi-Ohana N \& Orly J 2007 Transcriptional regulation of the cholesterol side chain cleavage cytochrome P450 gene (CYP11A1) revisited: binding of GATA, cyclic adenosine $3^{\prime}, 5^{\prime}$-monophosphate response element-binding protein and activating protein (AP)-1 proteins to a distal novel cluster of cis-regulatory elements potentiates AP-2 and steroidogenic factor-1-dependent gene expression in the rodent placenta and ovary. Molecular Endocrinology 21 948-962.

Shultz VD, Phillips S, Sar M, Foster PM \& Gaido KW 2001 Altered gene profiles in fetal rat testes after in utero exposure to di(n-butyl) phthalate. Toxicological Sciences 64 233-242.

Silva MJ, Reidy JA, Preau JL, Samandar E, Needham LL \& Calafat AM 2006 Measurement of eight urinary metabolites of di(2-ethylhexyl) phthalate as biomarkers for human exposure assessment. Biomarkers 11 1-13.

Sjoberg PO, Bondesson UG, Sedin EG \& Gustafsson JP 1985 Exposure of newborn infants to plasticizers. Plasma levels of di-(2-ethylhexyl) phthalate and mono-(2-ethylhexyl) phthalate during exchange transfusion. Transfusion 25 424-428.

Sjoberg P, Bondesson U, Gray TJ \& Ploen L 1986 Effects of di-(2-ethylhexyl) phthalate and five of its metabolites on rat testis in vivo and in in vitro. Acta Pharmacologica et Toxicologica 58 225-233.

Skakkebaek NE, Rajpert-De Meyts E \& Main KM 2001 Testicular dysgenesis syndrome: an increasingly common developmental disorder with environmental aspects. Human Reproduction 16 972-978.

Spitz MR, Sider JG, Pollack ES, Lynch HK \& Newell GR 1986 Incidence and descriptive features of testicular cancer among United States whites, blacks, and Hispanics, 1973-1982. Cancer 58 1785-1790.

Swan SH, Main KM, Liu F, Stewart SL, Kruse RL, Calafat AM, Mao CS, Redmon JB, Ternand CL, Sullivan S et al. 2005 Decrease in anogenital distance among male infants with prenatal phthalate exposure. Environmental Health Perspectives 113 1056-1061.

Teilmann G, Pedersen CB, Skakkebaek NE \& Jensen TK 2006 Increased risk of precocious puberty in internationally adopted children in Denmark. Pediatrics 118 e391-e399.

Travert C, Fofana M, Carreau S \& Le Goff D 2000 Rat Leydig cells use apolipoprotein E depleted high density lipoprotein to regulate testosterone production. Molecular and Cellular Biochemistry 213 51-59.

Venepally P \& Waterman MR 1995 Two Sp1-binding sites mediate CAMPinduced transcription of the bovine CYP11A gene through the protein kinase A signaling pathway. Journal of Biological Chemistry 270 25402-25410.

Venkata NG, Robinson JA, Cabot PJ, Davis B, Monteith GR \& RobertsThomson SJ 2006 Mono(2-ethylhexyl)phthalate and mono- $n$-butyl phthalate activation of peroxisome proliferator activated-receptors alpha and gamma in breast. Toxicology Letters 163 224-234.

Virtanen HE, Rajpert-De Meyts E, Main KM, Skakkebaek NE \& Toppari J 2005 Testicular dysgenesis syndrome and the development and occurrence of male reproductive disorders. Toxicology and Applied Pharmacology 207 501-505. 
Wang Y, Song L, Hong X, Cui L, Zhang Z, Xiao H, Zhou J \& Wang X 2006 Low concentrations mono-butyl phthalate stimulates steroidogenesis by facilitating steroidogenic acute regulatory protein expression in mouse Leydig tumor cells (MLTC-1). Chemico-Biological Interactions 164 15-24.

Ward JM, Peters JM, Perella CM \& Gonzalez FJ 1998 Receptor and nonreceptor-mediated organ-specific toxicity of di(2-ethylhexyl)phthalate (DEHP) in peroxisome proliferator-activated receptor alpha-null mice. Toxicologic Pathology 26 240-246.

Weiss J, Axelrod L, Whitcomb RW, Harris PE, Crowley WF \& Jameson JL 1992 Hypogonadism caused by a single amino acid substitution in the beta subunit of luteinizing hormone. New England Journal of Medicine 326 179-183.

Wing TY, Ewing LL \& Zirkin BR 1984 Effects of luteinizing hormone withdrawal on Leydig cell smooth endoplasmic reticulum and steroidogenic reactions which convert pregnenolone to testosterone. Endocrinology 115 2290-2296.
Yeaman SJ 2004 Hormone-sensitive lipase - new roles for an old enzyme. Biochemical Journal 379 11-22.

Zhang G \& Veldhuis JD 2004 Requirement for proximal putative Sp1 and AP-2 cis-deoxyribonucleic acid elements in mediating basal and luteinizing hormone- and insulin-dependent in vitro transcriptional activation of the CYP17 gene in porcine theca cells. Endocrinology 145 2760-2766.

Zhang FP, Poutanen M, Wilbertz J \& Huhtaniemi I 2001 Normal prenatal but arrested postnatal sexual development of luteinizing hormone receptor knockout (LuRKO) mice. Molecular Endocrinology 15 172-183.

Received 11 October 2007

First decision 27 November 2007

Revised manuscript received 26 January 2008

Accepted 7 February 2008 